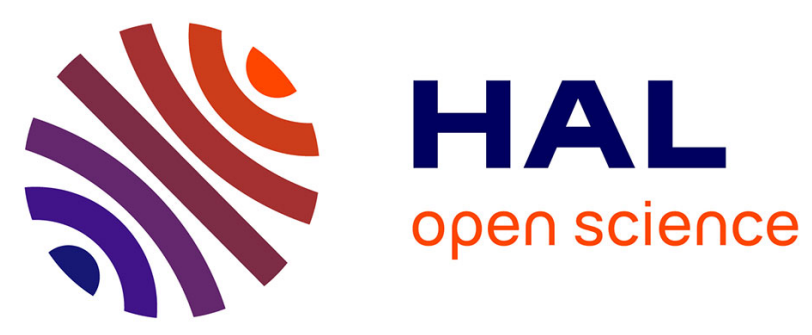

\title{
Use of human papillomavirus genotyping and biomarkers for targeted screening of anal dysplasia in human immunodeficiency virus-infected patients
}

Clarisse Dupin, Laurent Siproudhis, Sébastien Hénno, Sophie Minjolle, Cédric Arvieux, Pierre Tattevin

\section{To cite this version:}

Clarisse Dupin, Laurent Siproudhis, Sébastien Hénno, Sophie Minjolle, Cédric Arvieux, et al.. Use of human papillomavirus genotyping and biomarkers for targeted screening of anal dysplasia in human immunodeficiency virus-infected patients. Digestive and Liver Disease, 2015, 47 (5), pp.423-428. 10.1016/j.dld.2015.01.150 . hal-01147275

HAL Id: hal-01147275

https://hal-univ-rennes1.archives-ouvertes.fr/hal-01147275

Submitted on 22 Oct 2015

HAL is a multi-disciplinary open access archive for the deposit and dissemination of scientific research documents, whether they are published or not. The documents may come from teaching and research institutions in France or abroad, or from public or private research centers.
L'archive ouverte pluridisciplinaire HAL, est destinée au dépôt et à la diffusion de documents scientifiques de niveau recherche, publiés ou non, émanant des établissements d'enseignement et de recherche français ou étrangers, des laboratoires publics ou privés. 
Use of human papillomavirus genotyping and biomarkers for targeted screening of anal dysplasia in human immunodeficiency virus-infected patients

Clarisse Dupin, ${ }^{\mathrm{a}, \mathrm{b}}$ Laurent Siproudhis, ${ }^{\mathrm{b}, \mathrm{c}}$ Sébastien Henno, ${ }^{\mathrm{b}, \mathrm{d}}$ Sophie Minjolle, ${ }^{\mathrm{a}, \mathrm{b}}$ Cédric Arvieux, ${ }^{\mathrm{b}, \mathrm{e}}$ Pierre Tattevin ${ }^{\mathrm{b}, \mathrm{e}}$

Department of Virology, Pontchaillou University Hospital, Rennes, France ${ }^{\mathrm{a}}$; Université Rennes-I, Rennes, France ${ }^{\mathrm{b}}$;

Gastroenterology Unit, Pontchaillou University Hospital, Rennes, France ${ }^{c}$; Department of Pathology, Pontchaillou University Hospital, Rennes, France ${ }^{d}$; Infectious Diseases and Intensive Care Unit, Pontchaillou University Hospital, Rennes, France ${ }^{e}$

Running Head Screening for anal dysplasia in HIV patients

Conflicts of interests PT has served on the board for Bristol Myers Squibb, and Janssen, and has received payment for lectures from Viiv Healthcare, Bristol Myers Squibb, and Janssen. CA has served on the board for Bristol Myers Squibb, Viiv Healthcare, and Gilead science, and has received payment for lectures from Viiv Healthcare. CM have received payment for lectures from Bristol Myers Squibb, Viiv Healthcare, and Janssen.

Address correspondence to Prof. Laurent Siproudhis Gastroenterology Unit CHU PONTCHAILLOU 35033 RENNES Cedex 9 Tel +33299284311 Fax +33299282404 mail, laurent.siproudhis@chu-rennes.fr 
FUNDING Hologic (Inc. Bedford, MA, USA) offered the test kits for E6/E7 viral mRNA detection of 14 high risk HPV types (APTIMA assay). There was no other funding. 


\section{ABSTRACT}

Background. Screening for anal dysplasia in human immunodeficiency virus (HIV)-infected patients is not standardized. Highresolution imaging is not adequate for mass screening, and anal cytology requires expertise. New biomarkers, selected because of their use in cervical cancer mass screening, have been originally tested for targeted and easy-to-perform screening. Methods. 120 HIV-infected individuals (males $96.4 \%$, mean age $47 \pm 11$ years) were referred for clinical examination, anoscopy, and cytological

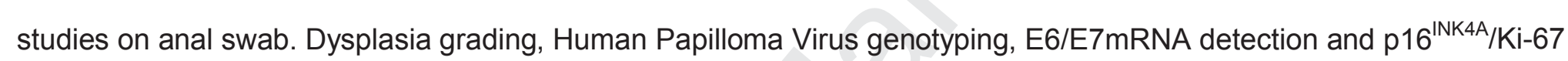
immunostaining were performed. High-grade lesions were histologically confirmed by anal biopsies after high-resolution anoscopy. Results. Among the 120 anal swabs analysed, 36 (30\%) had low grade, and 6 (5\%) had high-grade lesions. Virus genotype was identified in 88 patients (73.3\%), and 77 (64.2\%) were positive for high-risk genotype(s). High-risk genotype was associated to lowgrade or high-grade lesions with a sensitivity of 0.93 , and a specificity of 0.51 . For E6/E7mRNA, sensitivity and specificity for lowgrade and high-grade lesions were, respectively, 0.88 , and 0.78 . Combination of genotyping, E6/E7mRNA and $\mathrm{p} 16^{\mathrm{INK} 4 \mathrm{~A}} / \mathrm{Ki}-67$ appropriately ruled out dysplasia in $55 \%$ of patients. Conclusions. Three routine biomarkers may avoid unnecessary invasive procedures with the perspective of an improvement of patient compliance. A decision making algorithm, based on the combination of these 3 biomarkers, is proposed.

Key Words: HIV, HPV, anal dysplasia, high-risk HPV genotypes, high-risk HPV E6/E7 mRNA, p16 ${ }^{\text {INK4A } / K i-67}$ 


\section{INTRODUCTION}

The incidence of anal cancer has dramatically increased over the last decade in high-risk groups, including men who have sex with men (MSM), women with a previous history of cervical or vulvar cancer, and immunocompromised patients, especially those who are Human Immunodeficiency Virus (HIV)-infected (1-4). Several series estimated that the risk of anal cancer in HIV-infected MSM is comparable to the risk of cervical cancer in the general female population $(5,6)$. As for cervical cancers, intra-epithelial lesions induced by human papillomavirus (HPV) precede invasive anal cancer. Studies on the prevalence of HPV and its association to dysplasia in anal samples have demonstrated that both HPV and cytological abnormalities are common in high-risk populations. The overall prevalence of HPV infection in anal carcinoma was estimated at 85-97\%, HPV-16 being the most frequent genotype, found in $\sim 75 \%$ of cases $(7,8)$. Studies based on systematic cytology of anal swabs yield a much greater burden of abnormal findings than studies based on biopsies restricted to macroscopic lesions. In a large prospective study of HIV-infected MSM, the incidence of anal intra epithelial neoplasm was $37 \%$ over a 3 -year period (9). The prevalence of abnormal cytology ranges from $30 \%$ to $67 \%$ in these populations, and high-grade squamous intra-epithelial lesions (H-SIL) are found in $5-24 \%$.

These data advocate for the implementation of systematic screening for anal neoplasia in specific groups $(4,10)$. However, screening for anal dysplasia in high-risk populations is neither universally recommended, nor standardized. French guidelines recommend annual anoscopy in HIV-infected MSM, and in HIV-infected women with HPV-related genital lesions, and encourages systematic cytological studies of anal swabs during these screening (11), but these recommendations are poorly implemented for the following reasons: i) the number of specialized clinics offering expert evaluation and anoscopy is not sufficient in most areas; ii) this invasive procedure may be poorly tolerated by patients, and time-consuming for proctologists; iii) most pathologists are not familiar with anal cytology. In addition, both methods (i.e. anoscopy and cytological studies on anal swab) have questionable 
reproducibility and sensitivity to detect dysplasia of the anal canal. Testing several biomarkers, Wentzensen et al. found that HPV DNA genotyping and p16/Ki-67 on anal swabs had the highest sensitivity (92-100\%) for the detection of anal dysplasia in high-risk patients (12). In order to improve the efficiency of screening programs, the aims of the present study were two-fold: i) to evaluate the diagnostic accuracy of these biomarkers, and ii) to determine their potential use for targeted screening of anal dysplasia in HIVinfected patients.

\section{MATERIALS AND METHODS}

Study design. This cross-sectional study was conducted in the Rennes University Hospital, a tertiary care teaching hospital which serves as the referral centre for HIV-infected patients, and for anal pathology in the area (Western France, catchment population estimated at one million inhabitants). All HIV-infected patients were invited for anal neoplasia screening at the department of proctology, with special emphasis in MSM and women with HPV-related genital lesions, according to national guidelines. The first visit consisted in clinical examination, digital rectal examination, anoscopy, and collection of anal swabs for cytological studies. Data about life style and HIV disease were collected using a standardized questionnaire: gender, age, sexual activity, past history of sexually transmitted infection(s), and HIV-related parameters, including CDC stage, antiretroviral treatment (ART), CD4 cell counts, and HIV viral load. Before anoscopy, two Dacron swabs were collected from the anal canal and immediately suspended into ThinPrep PreservCyt medium (Hologic, Inc. Bedford, MA, USA): one was sent for cytology and immunohistochemistry studies, the other one for virological analysis. Specimens were maintained at $+4^{\circ} \mathrm{C}$ before processing for analyses or aliquoted and stored at $80^{\circ} \mathrm{C}$. All patients diagnosed with abnormal cytology through this first step underwent high-resolution anoscopy (HRA), and guided- 
biopsies were performed for histological studies if lesions were suspected, using acetic acid and Lugol's solution for better visualization. No biopsy was obtained from patient with normal cytology.

Cytology and histology. Two slides were prepared with the same medium. One was stained for cytology and the other one for immunochemistry. The pathologist who analysed samples has a long-standing experience in the analysis of anal samples, and was blinded to the results of biomarkers (HPV genotype, HPV E6/E7 mRNA and p16/Ki-67). Cytology grades were reported according to the Bethesda classification: no intraepithelial lesion (NIL), atypical squamous cell of undetermined significance (ASCUS), low-grade or high-grade squamous intraepithelial lesions (L-SIL or H-SIL) (13). The same pathologist classified histology as normal, low- or high-grade intra-epithelial lesions.

p16 ${ }^{\text {INK4A } / K i-67 ~ d u a l ~ s t a i n i n g . ~ A l l ~ s p e c i m e n s ~ w e r e ~ t e s t e d ~ f o r ~ d u a l ~ i m m u n o s t a i n i n g ~ p 16 ~} 16^{\text {INK4A } / K i-67 ~ C I N t e c ~}{ }^{\circledR}$ PLUS (Roche, MTM laboratories AG, Heidelberg, Germany), according to the manufacturer's instructions. Protein p16 ${ }^{\text {INK4A }}$ is a cell cycle regulatory protein overexpressed in high risk (hr) HPV persistent infection, and Ki-67 is a proliferation marker. The kit is a combination of two antibodies against $\mathrm{p} 16^{\mathrm{INK} 4 \mathrm{~A}}$ and Ki-67 used in the same slide, with different chromogens. The presence of at least one double-stained cell is interpreted as a positive test.

HPV DNA detection and genotyping. DNA testing was performed using the PreservCyt medium: $200 \mu \mathrm{L}$ were used for DNA extraction on MagNA Pure LC (Roche, Bâle, Switzerland). Anal specimens were tested for 35 HPV genotypes with CLART Human Papillomavirus 2 (Genomica, Madrid, Spain), a commercial kit for the detection of 15 low risk (Ir) HPV (6, 11, 40, 42, 43, 44, 54, 61, 62, 71, 72, 81, 83, 84, 89), and 20 high risk (hr) $\operatorname{HPV}(16,18,26,31,33,35,39,45,51,52,53,56,58,59,66,68,70,73$, 82, 85). The tests included a cellular control and an internal control. Microarray studies were analyzed using Clinical Arrays Reader 
(Genomica). A sample of $2 \mathrm{~mL}$ of each liquid-based medium was then frozen at $-80^{\circ} \mathrm{C}$. A hr-HPV DNA test was considered positive if at least one hr-HPV genotype was detected.

High-risk (hr) HPV E6/E7 mRNA detection. Specimens were tested for E6/E7 mRNA using HPV APTIMA assay (Hologic) on the PANTHER System, which detects E6/E7 viral mRNA of $14 \mathrm{hr}-\mathrm{HPV}$ types collectively by transcription-mediated amplification $(16,18,31,33,35,39,45,51,52,56,58,59,66,68)$. An aliquot of $1 \mathrm{~mL}$ of each sample was transferred into the APTIMA transfer tube and introduced into the PANTHER system without any other manipulation. According to the manufacturer's instructions, a cervix sample specimen is considered positive when the value of the signal-to-cut-off ratio $(S / C O)$ is $>1$. Because there is no validated S/CO threshold for anal samples, we reported the quantitative result of the hr-HPV E6/E7 mRNA test, and empirically used a conservative S/CO ratio threshold of 6 . To validate this threshold, we tested HPV DNA negative samples and found that they all were either negative for hr-HPV E6/E7 mRNA, or had a S/CO ratio $<6$.

Ethics. The database was authorized by the national regulatory institution, Commission Nationale Informatique et Liberté (CNIL n¹412467), and the study was approved by our institutional review board (N09-14). All participants provided written informed consent.

Statistical analysis. Mean and standard deviation were used to describe quantitative variables; number and percentage were used to describe qualitative variables. Differences between groups were measured using non-parametric tests where appropriate (Wilcoxon, Pearson, Chi2 or MacNemar). A $P$ value $<0.05$ was considered significant. The performance of $\mathrm{p} 16^{\mathrm{INK} 4 \mathrm{~A}} / \mathrm{Ki}$ 67 dual staining, hr-HPV DNA, and hr-HPV E6/E7 mRNA for the diagnosis of L-SIL and H-SIL was estimated. Statistical analyses were performed using JMP ${ }^{\circledR}$ Pro 9.0.2, 2010 (SAS Institute Inc., Cary, North Carolina, USA). 


\section{RESULTS}

Study participants. Between October 2010 and November 2011, 120 HIV-infected patients were enrolled in this cross-sectional study. The main characteristics of the study population are summarized in Table 1 . The mean age was $47 \pm 11$ years (range, 21-79). Among the 108 men, 89 (82.4\%) were MSM. All patients underwent a clinical examination of the peri-anal skin and anal canal through an anoscope. Macroscopic signs of HPV infection were observed in 20 patients $(16.7 \%)$, including external condyloma $(n=12)$, and/or endocanal lesions $(n=13)$. There was no ulceration and no clinical cancer.

Cytological findings. Among the 120 anal swabs analyzed, 51 (42.5\%) yielded NIL, 27 (22.5\%) ASC-US, 36 (30\%) L-SIL, and $6(5 \%) \mathrm{H}$-SIL. All patients with a cytological diagnosis of H-SIL were histologically confirmed, with high-grade intra-epithelial dysplasia identified through HRA-guided biopsies. No invasive cancer was diagnosed at baseline.

HPV DNA genotyping, hr-HPV E6/E7 mRNA detection, and p16 ${ }^{\mathrm{INK} 4 \mathrm{~A}} / \mathrm{Ki}-67$ dual staining. HPV genotype was identified in 88 patients (74.6\%), no HPV was found in 30 patients (25.4\%), and HPV was detected, but could not be genotyped in the remaining two patients (both had NIL). Table 2 highlights the prevalence of high risk genotypes according to the cytological status. The following genotypes were the most common that differed according to cytological status: $16,31,35,51,52$. Table 3 summarizes the mean number of different genotypes and the prevalence of hr-HPV DNA according to cytological status. The number of hr-HPV genotypes was significantly associated with Bethesda grading. Among specimens positive for at least one hr-HPV type, the prevalence of multiple infections was $75.3 \%$, with a mean number of $3.5 \pm 2.4$ different genotypes (range, 2-11). Hr-HPV DNA was significantly associated with cytological grade, as were positivity of hr-HPV E6/E7 mRNA, mean S/CO value, and p16 ${ }^{\text {INK4A } / K i-67}$ dual staining. Due to sub-optimal quality of samples slides and lack of material, this latter test could be performed in only 74 patients, and was not interpretable in 10 of these. 


\section{Diagnostic accuracy of biomarkers.}

The diagnosis accuracy of the three tests has been highlighted in the Table 4. For the diagnosis of L-SIL or H-SIL, the identification of at least one hr-DNA genotype exhibited a sensitivity (Se) of 0.93 , a specificity ( $\mathrm{Sp}$ ) of 0.51 , a negative predictive value (NPV) of 0.88, and a positive predictive value (PPV) of 0.66. High risk HPV E6/E7 mRNA assay had Se, Sp, NPV, and PPV of, respectively, $0.88,0.78,0.87$, and 0.80 . For $16^{\mathrm{INK} 4 \mathrm{~A}} / \mathrm{Ki}-67$ testing, Se, Sp, NPV, and PPV were $0.64,0.90,0.68$, and 0.88 , respectively. Among the 41 patients with no hr-HPV (34.7\%), 3 (7.3\%) had L-SIL, but none had H-SIL. Of the 23 patients (31.1\%) with positive p16 INK4A/Ki-67 testing, 16 (69.6\%) had L-SIL, and $3(13 \%)$ had H-SIL. Fig. 1 depicts the triage of our population based on the results of these tests. Briefly, a negative result on hr-HPV E6/E7 mRNA test could have avoided subsequent evaluation in one half of the population study, as $91.2 \%$ of them had no dysplasia and none had H-SIL. On the other hand, in patients positive for hr-HPV E6/E7

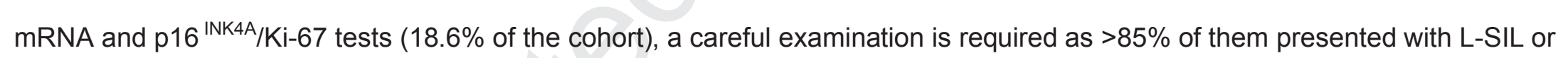
$\mathrm{H}$-SIL. The same would apply to the $14.4 \%$ of patients with negative $\mathrm{p} 16^{\mathrm{INK} 4 \mathrm{~A}} / \mathrm{Ki}-67$ but carrying HPV-16 or HPV-18 DNA, as this combination was associated to dysplasia in $\sim 50 \%$ of cases. A last population at low risk of anal dysplasia was identified in this cohort: patients with negative p16 ${ }^{\text {INK4A } / K i-67, ~ n o ~ H P V-16 ~ o r ~ H P V-18, ~ a n d ~<3 ~ h r-H P V ~ g e n o t y p e s: ~ o n l y ~ o n e ~ o u t ~ o f ~} 8$ had dysplasia (L-

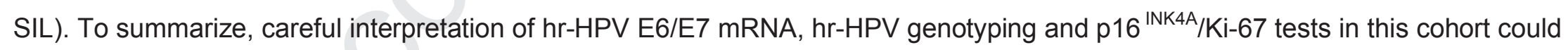
accurately classify the risk of dysplasia in $90.8 \%$ of patients (Fig. 1).

\section{DISCUSSION}

The increasing incidence of anal cancer in HIV-infected patients, often diagnosed at a late stage, advocates for the implementation of systematic or targeted screening of high-risk patients. However, no strategy for anal cancer screening has been validated thus 
far in this population. Hence, practices vary widely from one cohort to another, as a function of patients will, scientific interest of the physicians in charge, and availability of specialized centres qualified for anal cancer screening. In addition, although HRA with macroscopically-guided biopsies is highly specific, its sensitivity was recently challenged in a study comparing HRA with a combination of different cytological testing (12). Lastly, anal cytology requires pathologist expertise: Inter-agreement assessment has been recently found to be moderate-to-good in HIV-infected MSM (14), and the sensitivity and specificity of anal cytology has been shown to be $70-93 \%$ and $67-92 \%$, respectively, as compared with histological studies from biopsies (15-17). For H-SIL, NPV of anal cytology were excellent (mean, 85\%; range 76-92) in Nathan et al. series. Of note, these authors have shown that the sensitivity of anal swab increases with the extension of the disease, and reaches $86 \%$ when at least 2 quadrants are involved (17).

Referral to specialized centres performing HRA and cytology may be cost-effective in high-risk population, especially HIVinfected MSM and HIV-infected women with HPV-related genital lesions (18). However, reliable tests that would allow a preselection of this high-risk population would be most welcome, by decreasing the financial costs of systematic screening, the workload for specialized centres, and the number of patients undergoing these invasive, uncomfortable tests. On the one hand, biomarkers are costly (approximately 35 to 50 Euros per test); on the other, HRA is somewhat a long procedure (30-45 minutes), the assessment of elementary lesions needs a learning curve, and the material is costly (6000 to 18000 Euros).

Our study suggests that the combination of three biomarkers, hr-HPV E6/E7 mRNA, hr-HPV genotypes and p16 ${ }^{\text {INK4A } / K i-67, ~}$ would allow targeted screening of anal dysplasia in HIV-infected patients, by ruling out L-SIL and H-SIL in > 55\% of patients. It must be outlined that no case of H-SIL would have been overlooked with a strategy that would perform anal cytology and histology only in patients positive with either hr-HPV E6/E7 mRNA and/or p16 ${ }^{\text {INK4A } / K i-67 . ~ B y ~ c o n t r a s t, ~ t h e ~ g u i d e d-b i o p s i e s ~ w e r e ~ p e r f o r m e d ~ f o r ~}$ histological studies if lesions were suspected, using acetic acid and Lugol's solution for better visualization. According to ethical 
concerns, no biopsy was obtained from patients with normal cytology: in fact, biopsies are somewhat painful and they carry a bleeding risk.

We speculated that defining viral profiles and sensitive biomarkers might help to develop diagnostic strategies and tailored screening in high-risk groups. We selected candidate biomarkers of viral oncogenicity (hr-HPV DNA, hr-HPV E6/E7 mRNA) and cytological abnormalities ( $\mathrm{p} 16^{\mathrm{INK} 4 \mathrm{~A}} / \mathrm{Ki}-67$ ), which has already proved useful in screening of cervical cancer. They all can be routinely performed and automatized in a multicentre setting. More than $100 \mathrm{HPV}$ genotypes have been linked to anal carcinoma, with several high-risk subtypes identified, HPV-16 being the most common, although the proportion of non-HPV-16 oncogenic genotypes has increased in recent series (19). In our study, HPV-16 was found in 35\% of swabs positive for hr-HPV, and 6 other oncogenic genotypes were found in $>10 \%$ of patients: HPV $52,58,66,33,53$, and 51 . It emphasizes the need of genomic tests which detects all hr-HPV genotypes: the APTIMA assay is one of them. For screening purposes, biomarkers must primarily be sensitive, if they are to be used as 'rule-out' tests. In this regard, the detection of hr-HPV E6/E7 mRNA appears as a suitable test: in the study presented herein, one-half of the population had no detection of hr-HPV E6/E7 mRNA, and $91.2 \%$ of them had no dysplasia (neither L-SIL nor H-SIL). On the contrary, p16 ${ }^{\mathrm{INK} 4 \mathrm{~A}} / \mathrm{Ki}-67$ would not qualify as a good biomarker to rule out anal dysplasia, given its low sensitivity (0.64), but would be of interest as a confirmatory test, given its high specificity: only $7.7 \%$ of patients with positive $\mathrm{p} 16^{\mathrm{INK} 4 \mathrm{~A}} / \mathrm{Ki}-67$ had normal cytology. However, not all patients were tested because the material was no longer available when p16INK4A/Ki67 was retrospectively performed. These preliminary results must be confirmed by a prospective study.

Using three reproducible tests (hr-HPV E6/E7 mRNA, hr-HPV genotype and p16 $16^{\text {INK4A } / K i-67) ~ w i t h ~ n o ~ n e e d ~ f o r ~ e x p e r t i s e, ~ w e ~}$ selected 53 patients (44.9\%) who would be candidates for pathologist examination of anal swabs (Fig. 1). Of these, 36 (67.9\%) had L-SIL or H-SIL on anal cytology and 9 (17\%) presented dysplasia on subsequent examination, indicating the need for careful 
examination of the anal canal with guided biopsies. For the other half of this high-risk HIV-infected population, hr-HPV E6/E7 mRNA, and hr-HPV genotype could rule out anal dysplasia, and avoid further tests. The diagnostic test performance using a combined analysis was lacking in the present study. The aim of the present study was in fact to evaluate the accuracy of each biomarker, and the size of the study population does not allow the calculation of predictive values among small subgroups. We tried to design a simple algorithm in figure 2 which remains to be tested prospectively among a larger cohort in order to analyse the performance of a stepwise combination of tests.

This study has limitations, especially in the lack of systematic follow-up data in patients with ASC-US or L-SIL. However, studies of HPV clearance, co-infections or replacement by new HPV DNA subtypes are in progress in our centre. Changes in cytological status over time may be the result of subsequent infectious events, thus the evolution of cytological patterns remains speculative without concomitant follow-up of HPV status. Monitoring the rate of progression of various stages of anal dysplasia in a large HIV-positive cohort, de Pokomandy et al. found no regression of extensive untreated dysplasia, and a dramatic increase in the cumulative proportion of subjects with L-SIL or H-SIL at any time point since enrolment in the cohort (9). These data suggest that HPV clearance is not a frequent event in HIV-infected patients. Other limitations of our study include its monocentric design, and the absence of a validation cohort, as diagnostic algorithms tend to be less accurate when applied in other cohorts. In addition, as HRA and biopsies were only performed in patients with dysplasia, histological studies were not performed in the whole cohort.

However, to the best of our knowledge, only few studies on the yield of biomarkers for the screening of anal canal cancer in high-risk groups have been published (12, 20-22), and only one studied high-risk HPV E6/E7 mRNA and p16 INK4A/Ki-67 immunostaining simultaneously (12). All four studies published to date confirm that these biomarkers may be of interest for anal dysplasia screening, although further investigations are required to better define their respective added values. The study presented 
herein is the second where hr-HPV E6/E7 mRNA was detected with APTIMA assay, which detects 14 hr-HPV, and has been associated with improved diagnostic yield for cervical dysplasia $(23,24)$.

In summary, easy to perform, reproducible and non-invasive biomarkers, such as the identification of high-risk HPV E6/E7 mRNA, hr-HPV genotypes, and p16 $16^{\mathrm{INK} 4 \mathrm{~A}} / \mathrm{Ki}-67$ immunostaining on anal swab may be used for the screening of anal dysplasia in HIV-infected patients. In our study, their combination appropriately ruled out L-SIL and H-SIL in $>55 \%$ of patients. A simple algorithm of a stepwise testing (figure 2) remains to be tested prospectively among a larger cohort. The cost effectiveness strategies and the patient compliance need to be clarified in population studies. 


\section{ACKNOWLEDGEMENTS}

We are indebted to all the patients who participated in the study, and the health care workers who took care of them. 


\section{REFERENCES}

1. Piketty C, Darragh TM, Heard I, et al. High prevalence of anal squamous intraepithelial lesions in HIV-positive men despite the use of highly active antiretroviral therapy. Sexually transmitted diseases. 2004;31(2):96-9.

2. Hoots BE, Palefsky JM, Pimenta JM, et al. Human papillomavirus type distribution in anal cancer and anal intraepithelial lesions. International journal of cancer. 2009;124(10):2375-83.

3. Palefsky JM, Holly EA, Ralston ML, et al. Effect of highly active antiretroviral therapy on the natural history of anal squamous intraepithelial lesions and anal human papillomavirus infection. Journal of acquired immune deficiency syndromes. $2001 ; 28(5): 422-8$.

4. Conley L, Bush T, Darragh TM, et al. Factors associated with prevalent abnormal anal cytology in a large cohort of HIVinfected adults in the United States. The Journal of infectious diseases. 2010;202(10):1567-76.

5. Palefsky J. Human papillomavirus-related disease in people with HIV. Current opinion in HIV and AIDS. 2009;4(1):52-6.

6. Ferlay J, Parkin DM, Steliarova-Foucher E. Estimates of cancer incidence and mortality in Europe in 2008. European journal of cancer. 2010;46(4):765-81.

7. De Vuyst H, Clifford GM, Nascimento MC, et al. Prevalence and type distribution of human papillomavirus in carcinoma and intraepithelial neoplasia of the vulva, vagina and anus: a meta-analysis. International journal of cancer. 2009;124(7):1626-36.

8. Abramowitz L, Jacquard AC, Jaroud F, et al. Human papillomavirus genotype distribution in anal cancer in France: the EDiTH V study. International journal of cancer. 2011;129(2):433-9.

9. de Pokomandy A, Rouleau D, Ghattas G, et al. HAART and progression to high-grade anal intraepithelial neoplasia in men who have sex with men and are infected with HIV. Clinical infectious diseases. 2011;52(9):1174-81. 
10. Ciobotaru B, Leiman G, St John T, et al. Prevalence and risk factors for anal cytologic abnormalities and human papillomavirus infection in a rural population of HIV-infected males. Diseases of the colon and rectum. 2007;50(7):1011-6.

11. Morlat P. Ministère des Affaires Sociales et de la Sante, Conseil National du Sida, Agence Nationale de Recherches sur le SIDA et les Hépatites Virales. Prise en Charge Médicale des Personnes Vivant Avec le VIH. Recommandations du Groupe d'Experts. Rapport 2013. http://www.sante.gouv.fr/IMG/pdf/Rapport_Morlat_2013_Mise_en_ligne.pdf

12. Wentzensen N, Follansbee S, Borgonovo S, et al. Human papillomavirus genotyping, human papillomavirus mRNA expression, and p16/Ki-67 cytology to detect anal cancer precursors in HIV-infected MSM. AIDS. 2012;26(17):2185-92.

13. Solomon D, Davey D, Kurman R, et al. The 2001 Bethesda System: terminology for reporting results of cervical cytology. JAMA : the journal of the American Medical Association. 2002;287(16):2114-9.

14. Darragh TM, Tokugawa D, Castle PE, et al. Interrater agreement of anal cytology. Cancer cytopathology. 2012.

15. Fox PA, Seet JE, Stebbing J, et al. The value of anal cytology and human papillomavirus typing in the detection of anal intraepithelial neoplasia: a review of cases from an anoscopy clinic. Sexually transmitted infections. 2005;81(2):142-6.

16. Chiao EY, Giordano TP, Palefsky JM, et al. Screening HIV-infected individuals for anal cancer precursor lesions: a systematic review. Clinical infectious diseases. 2006;43(2):223-33.

17. Nathan M, Singh N, Garrett N, et al. Performance of anal cytology in a clinical setting when measured against histology and high-resolution anoscopy findings. AIDS. 2010;24(3):373-9.

18. Goldie SJ, Kuntz KM, Weinstein MC, et al. Cost-effectiveness of screening for anal squamous intraepithelial lesions and anal cancer in human immunodeficiency virus-negative homosexual and bisexual men. The American journal of medicine.

2000;108(8):634-41. 
19. Wong AK, Chan RC, Aggarwal N, et al. Human papillomavirus genotypes in anal intraepithelial neoplasia and anal carcinoma as detected in tissue biopsies. Modern pathology. 2010;23(1):144-50.

20. Salit IE, Tinmouth J, Chong S, et al. Screening for HIV-associated anal cancer: correlation of HPV genotypes, p16, and E6 transcripts with anal pathology. Cancer Epidemiol Biomarkers Prev. 2009;18(7):1986-92.

21. Silling S, Kreuter A, Hellmich M, et al. Human papillomavirus oncogene mRNA testing for the detection of anal dysplasia in HIV-positive men who have sex with men. J Clin Virol. 2012;53(4):325-31.

22. Phanuphak N, Teeratakulpisarn N, Keelawat S, et al. Use of human papillomavirus DNA, E6/E7 mRNA, and p16 immunocytochemistry to detect and predict anal high-grade squamous intraepithelial lesions in HIV-positive and HIVnegative men who have sex with men. PLoS One. 2013;8(11):e78291.

23. Szarewski A, Ambroisine L, Cadman L, et al. Comparison of predictors for high-grade cervical intraepithelial neoplasia in women with abnormal smears. Cancer Epidemiol Biomarkers Prev. 2008;17(11):3033-42.

24. Burger EA, Kornor H, Klemp M, et al. HPV mRNA tests for the detection of cervical intraepithelial neoplasia: a systematic review. Gynecol Oncol. 2011;120(3):430-8. 
FIG 1: Triage of human immunodeficiency virus-infected patients screened for anal dysplasia using a combination of 3 biomarkers

bold letters: patients with high risk of dysplasia. hr-HPV, High-risk Human Papilloma Virus; ; E6/E7 mRNA : hr-HPV E6/E7 mRNA detection on cytology, p16INK4A/Ki-67: p16INK4A/Ki-67 dual staining on cytology

FIG 2 A decision-making algorithm to screen human immunodeficiency virus-infected patients for anal lesions.

hr-HPV, High-risk Human Papilloma Virus; HRA: High Resolution Anoscopy; E6/E7 mRNA : hr-HPV E6/E7 mRNA detection on cytology, p16INK4A/Ki-67: p16INK4A/Ki-67 dual staining on cytology 
TABLE 1 Characteristics of enrolled patients ( $\mathrm{N}=120)$

\begin{tabular}{|c|c|}
\hline Characteristics & Number of patients (\%) \\
\hline Male Gender & $108(90)$ \\
\hline \multicolumn{2}{|l|}{ Age (years) } \\
\hline 20-29 & $6(5)$ \\
\hline 30-39 & $19(16)$ \\
\hline $40-49$ & $51(43)$ \\
\hline $50-59$ & $26(21)$ \\
\hline$>60$ & $18(15)$ \\
\hline \multicolumn{2}{|l|}{ HIV infection stage } \\
\hline A & $72(60)$ \\
\hline B & $19(15.8)$ \\
\hline $\mathrm{C}$ & $28(23.4)$ \\
\hline Undetermined & $1(0.8)$ \\
\hline \multicolumn{2}{|l|}{ Current cART } \\
\hline Yes & $112(93.3)$ \\
\hline No & $5(4.2)$ \\
\hline Unknown & $3(2.5)$ \\
\hline \multicolumn{2}{|c|}{ Nadir of CD4 cell count (cell/mm3) } \\
\hline$<200$ & $55(45.8)$ \\
\hline $200-400$ & $42(35)$ \\
\hline$>400$ & $22(18.4)$ \\
\hline Undetermined & $1(0.8)$ \\
\hline \multicolumn{2}{|c|}{ HIV load at enrolment (copies/ml) } \\
\hline$<40$ & $93(77.5)$ \\
\hline $40-100$ & $11(9.2)$ \\
\hline$>100$ & $15(12.5)$ \\
\hline Undetermined & $1(0.8)$ \\
\hline \multicolumn{2}{|l|}{ Smoking } \\
\hline Current and/or past & $70(58.3)$ \\
\hline Never & $48(40)$ \\
\hline
\end{tabular}




\section{Undetermined}

Men who have Sex with Men

Yes

No

Unknown

Injection drug use

$89(82.4)$

$18(16.7)$

$1(0.9)$

$8(6.7)$

\section{HIV, human immunodeficiency virus; cART, combination of antiretrovirals}


TABLE 2 High-risk Human Papilloma Virus genotypes according to cytological status, number (\%)

\begin{tabular}{|c|c|c|c|c|c|}
\hline $\begin{array}{l}\text { Hr-HPV } \\
\text { genotype }\end{array}$ & $\begin{array}{c}\text { NIL } \\
(\%, n=49)\end{array}$ & $\begin{array}{l}\text { ASC-US } \\
(\%, n=27)\end{array}$ & $\begin{array}{c}\text { L-SIL } \\
(\%, n=36)\end{array}$ & $\begin{array}{c}\text { H-SIL } \\
(\%, n=6)\end{array}$ & $\begin{array}{c}\text { Total } \\
(\%, n=118)\end{array}$ \\
\hline $16^{*}$ & 8(16) & $2(7.4)$ & $16(44.4)$ & $5(83.3)$ & $31(25.8)$ \\
\hline $52 *$ & $3(6)$ & $4(14.8)$ & $8(22.2)$ & $3(50)$ & 18(15) \\
\hline 58 & $6(12)$ & 1(3.7) & $10(27.7)$ & 1(16.6) & 18(15) \\
\hline 66 & $4(8)$ & $7(25.9)$ & $5(13.8)$ & $1(16.6)$ & $17(14.2)$ \\
\hline 33 & $4(8)$ & $2(7.4)$ & 6(16.6) & 2(33.3) & 14(11.7) \\
\hline 53 & $4(8)$ & $1(3.7)$ & $8(22.2)$ & 1(16.6) & $14(11.7)$ \\
\hline $51^{*}$ & 1(2) & $2(7.4)$ & $10(27.7)$ & $0(0)$ & $13(10.8)$ \\
\hline 70 & $3(6)$ & $3(11.1)$ & $4(11.1)$ & 2(33.3) & $12(10)$ \\
\hline $35^{*}$ & 1(2) & $2(7.4)$ & $6(16.6)$ & 2(33.3) & 11(9.2) \\
\hline $31^{*}$ & 1(2) & $1(3.7)$ & $7(19.4)$ & 1(16.6) & $10(8.3)$ \\
\hline 59 & $3(6)$ & $0(0)$ & $6(16.6)$ & 1(16.6) & 10(8.3) \\
\hline 18 & $3(6)$ & $3(11.1)$ & $2(5.5)$ & $0(0)$ & $8(6.7)$ \\
\hline 56 & $3(6)$ & $1(3.7)$ & $2(5.5)$ & 1(16.6) & $7(5.8)$ \\
\hline 39 & $3(6)$ & 1(3.7) & $2(5.5)$ & $0(0)$ & 6(5) \\
\hline 68 & $1(2)$ & $2(7.4)$ & $2(5.5)$ & 1(16.6) & 6(5) \\
\hline 82 & $0(0)$ & $2(7.4)$ & $2(5.5)$ & 1(16.6) & $5(4.2)$ \\
\hline 26 & $0(0)$ & 1(3.7) & $2(5.5)$ & $0(0)$ & $3(2.5)$ \\
\hline 45 & $0(0)$ & 1(3.7) & $1(2.7)$ & $0(0)$ & $2(1.7)$ \\
\hline 73 & $1(2)$ & $0(0)$ & $0(0)$ & $0(0)$ & $1(0.8)$ \\
\hline 85 & 1(2) & $0(0)$ & $0(0)$ & $0(0)$ & $1(0.8)$ \\
\hline
\end{tabular}


Hr HPV High-risk Human Papilloma Virus genotypes are classified according to their prevalence in the study.

* Cytology patterns significantly different with p<0.05; NIL, no intraepithelial lesion; ASC-US, atypical squamous cell of undetermined significance; L-SIL, low-grade squamous intraepithelial lesions; H-SIL, high-grade squamous intraepithelial lesion 
TABLE 3 High-risk Human Papilloma Virus genotypes and biomarkers according to cytological status

\begin{tabular}{|c|c|c|c|c|c|}
\hline & $\begin{array}{l}\text { NIL } \\
n=49\end{array}$ & $\begin{array}{c}\text { ASC-US } \\
\mathbf{n}=27\end{array}$ & $\begin{array}{c}\text { L-SIL } \\
\text { n=36 }\end{array}$ & $\begin{array}{c}\text { H-SIL } \\
n=6\end{array}$ & $\begin{array}{c}\text { Total } \\
\text { n=118 }\end{array}$ \\
\hline Mean number of hr-HPV DNA genotypes per patient & $1.4 \pm 2.1$ & $1.9 \pm 1.9$ & $3.8 \pm 2.4$ & $4.7 \pm 3.1$ & $2.4 \pm 2.5$ \\
\hline >2 different hr-HPV DNA genotypes, number (\%) & $8(16.3)$ & $10(37)$ & $24(66.7)$ & $5(83.3)$ & $47(39.8)$ \\
\hline hr-HPV DNA, number positive (\%) & $21(42.9)$ & $17(63)$ & $33(91.7)$ & $6(100)$ & $77(65.3)$ \\
\hline Mean S/Co of hr-HPV E6/E7 mRNA & $3.7 \pm 7.2$ & $6.5 \pm 6.9$ & $14.2 \pm 9.2$ & $20.7 \pm 10.1$ & $8.3 \pm 9.5$ \\
\hline hr-HPV E6/E7 mRNA, number positive (\%) & $11(22.5)$ & $13(48.1)$ & $31(86.1)$ & $6(100)$ & $60(50)$ \\
\hline p16/Ki-67, number positive/tested (\%) & $1 / 13(7.7)$ & $3 / 25(12)$ & $16 / 31(44.4)$ & $3 / 5(60)$ & 23/74 (31.1) \\
\hline
\end{tabular}

\section{Cytology patterns are significantly different for each parameter $(\mathbf{P}<\mathbf{0 . 0 0 0 1})$}

hr-HPV, High-risk Human Papilloma Virus; NIL, no intraepithelial lesion; ASC-US, atypical squamous cell of undetermined significance; L-SIL, low-grade squamous intraepithelial lesions; H-SIL, high-grade squamous intraepithelial lesion; S/CO, signal-to-cut-off ratio 
TABLE 4 Diagnostic accuracy of biomarkers in the diagnosis of anal dysplasia

\begin{tabular}{|c|c|c|c|c|}
\hline & Sensitivity & Specificity & $\begin{array}{l}\text { Negative } \\
\text { Predictive } \\
\text { Value }\end{array}$ & $\begin{array}{c}\text { Positive } \\
\text { Predictive } \\
\text { Value }\end{array}$ \\
\hline hr-HPV DNA genotype & 0.93 & 0.51 & 0.88 & 0.66 \\
\hline hr-HPV E6/E7 mRNA & 0.88 & 0.78 & 0.87 & 0.80 \\
\hline p16 ${ }^{\mathrm{INK} 4 \mathrm{~A}} / \mathrm{Ki}-67$ dual staining & 0.64 & 0.90 & 0.68 & 0.88 \\
\hline
\end{tabular}

hr-HPV. High-risk Human Papilloma Virus; 


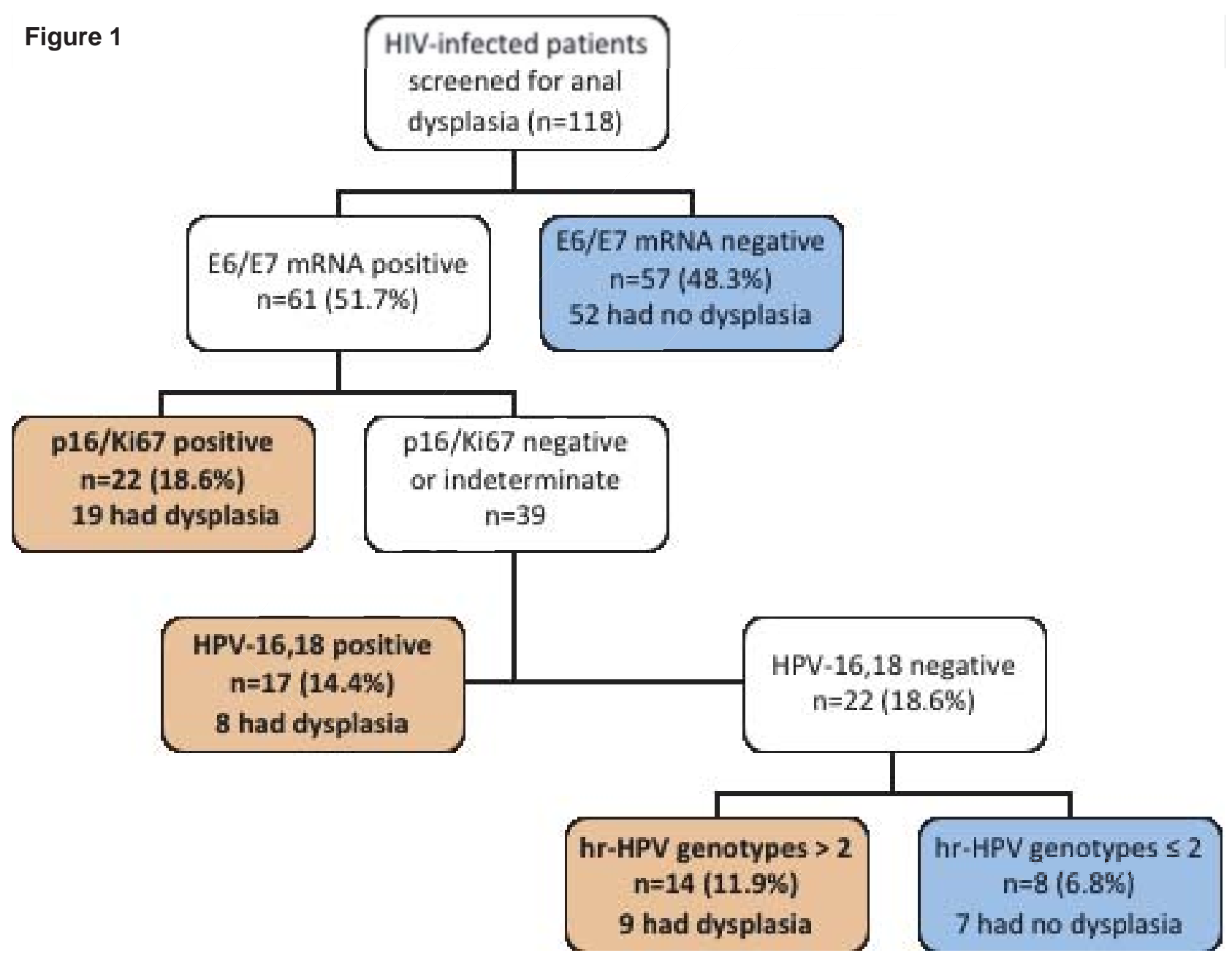




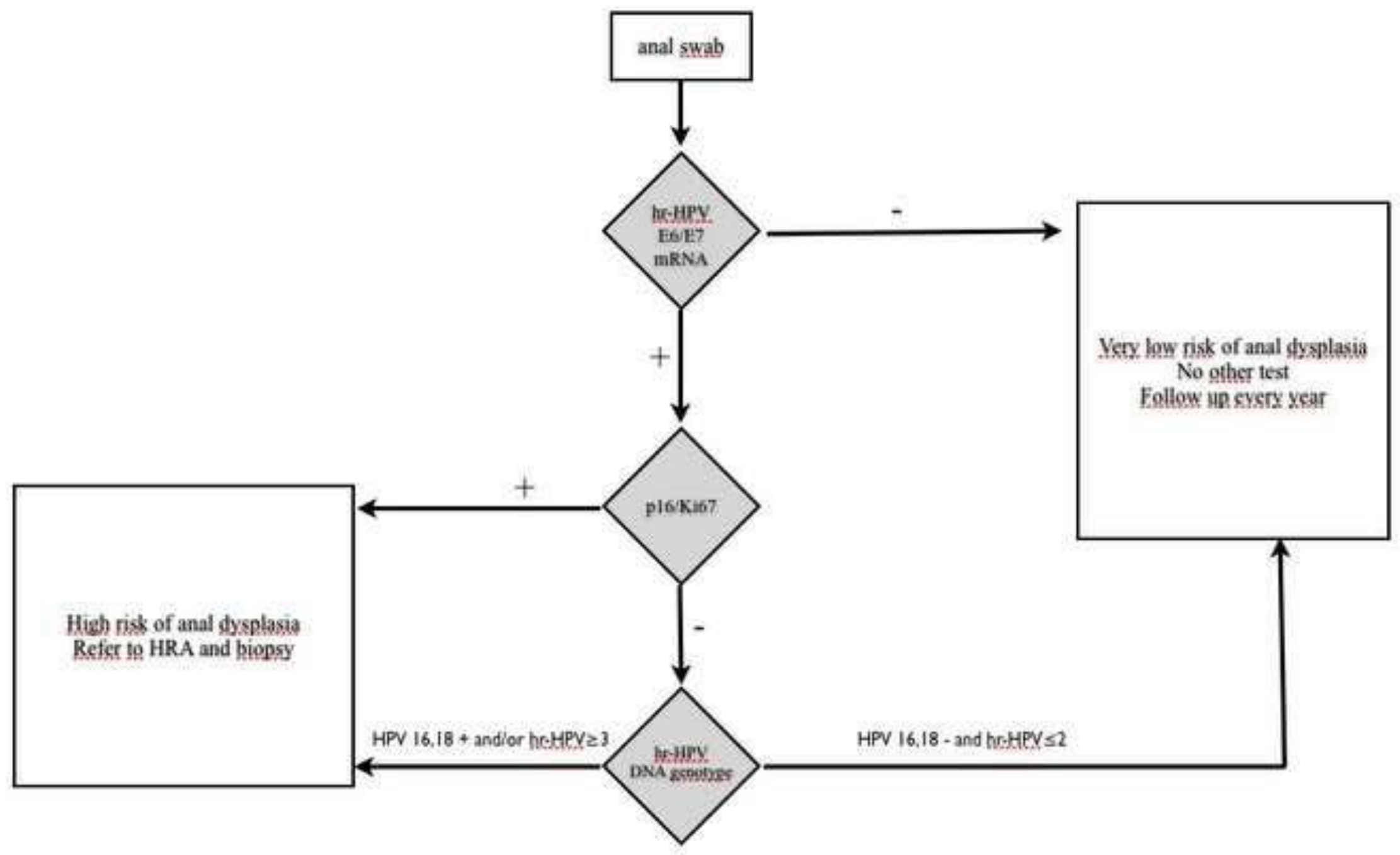

